\title{
Does the condition of the mouth and teeth affect the ability to eat certain foods, nutrient and dietary intake and nutritional status amongst older people?
}

\author{
A Sheiham ${ }^{1, *}$ and J Steele ${ }^{2}$ \\ 'Department of Epidemiology \& Public Health, University College London Medical School, London WC1E 6BT, UK: \\ ${ }^{2}$ The Dental School, University of Newcastle upon Tyne, Framlington Place, Newcastle upon Tyne NE2 4BW, UK
}

Submitted 29 September 2000: Accepted 27 November 2000

\begin{abstract}
Objectives: To assess how the dental status of older people affected their stated ability to eat common foods, their nutrient intake and some nutrition-related blood analytes.

Design: Cross-sectional survey part of nation-wide British National Diet and Nutrition Survey: people aged 65 years and older. Data from a questionnaire were linked to clinical data and data from four-day weighed dietary records. Two separate representative samples: a free-living and an institutional sample. Seven-hundredand-fifty-three free-living and 196 institution subjects had a dental exam and interview.

Results: About one in five dentate (with natural teeth) free-living people had difficulty eating raw carrots, apples, well-done steak or nuts. Foods such as nuts, apples and raw carrots could not be eaten easily by over half edentate (without natural teeth but with dentures) people in institutions. In free-living, intakes of most nutrients and fruit and vegetables were significantly lower in edentate than dentate. Perceived chewing ability increased with increasing number of teeth. Daily intake of non-starch polysaccharides, protein, calcium, non-haem iron, niacin, vitamin $\mathrm{C}$ and intrinsic and milk sugars were significantly lower in edentate. Plasma ascorbate and retinol were significantly lower in the edentate than dentate. Plasma ascorbate was significantly related to the number of teeth and posterior contacting pairs of teeth. Conclusions: The presence, number and distribution of natural teeth are related to the ability to eat certain foods, affecting nutrient intakes and two biochemical measures of nutritional status.
\end{abstract}

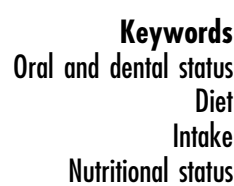

Most efforts to improve the diets of older people have been directed at health promotion and education, and at changing catering practices. Nutritionists have paid relatively little attention to the impact of a biological factor that may inhibit the intake of certain foods: the teeth.

Although it may seem self-evident that the number and condition of teeth should influence food choice, diet and nutrition, there are remarkably few data on large populations to support this assumption and still fewer to indicate the nature of any relationship ${ }^{1-3}$. There is some evidence that an impaired dentition can affect individuals by causing dietary restrictions via chewing difficulty, possibly compromising nutritional status and well-being $^{4-6}$. There is also evidence that people who cannot chew or bite comfortably are less likely to consume high-fibre foods such as bread, fruit and vegetables, thereby risking reducing their intake of essential nutrients ${ }^{7}$. Chewing ability is highly correlated with the number of teeth, but the relationship is not linear ${ }^{8}$. Until recently, both the volume and the quality of evidence directly linking oral health with nutrition have been limited.

Chewing problems are relatively common. Of 1755 people aged 65 years or over, 13\% with impaired dentitions said that they 'often' or 'always' had problems biting or chewing in the previous three months and $10 \%$ experienced frequent limitations in the kinds or amounts of food eaten, while 9\% always perceived discomfort while eating? . One in five older people reported that oral conditions prevented them from eating the foods they would choose, $15 \%$ took longer to complete their meal 
and their enjoyment of food was limited by oral conditions, and 5\% avoided eating with other people because of chewing problems ${ }^{10}$. Edentulous subjects (people with no natural teeth who usually rely on complete dentures) were more affected than dentate people. People with xerostomia (dry mouth), which affects about $20 \%$ of older people ${ }^{11}$, also complained of difficulties eating certain foods ${ }^{11,12}$. There is clearly the potential for the condition of the mouth and teeth to have an adverse affect on nutrition.

Oral health status may be a particularly important factor for the nutrition of older people. Extensive or even complete tooth loss is very common in the elderly and there is some evidence that this may alter food choice, resulting in lower intakes for key nutrients such as iron and fibre ${ }^{4,7,13-16}$. Tooth loss has been associated with a lower intake of hard-to-chew foods such as apples and carrots. Edentate people have been shown to consume fewer vegetables and fruit, less fibre and carotene, and more cholesterol, saturated fats and calories than their dentate counterparts ${ }^{17-19}$. Studies which have analysed the effects of dental status on the consumption of nonstarch polysaccharides reported a reduction in intake with tooth loss in older adults ${ }^{15,18,20}$. Not only do older people have fewer natural teeth and are more likely to wear complete dentures than the rest of the population, they are also vulnerable to dietary restrictions for other reasons (disability, medical or social conditions).

All of the existing evidence linking oral health and nutrition has tended to suffer from problems of small or poorly representative samples, or of difficulty with data collection or analysis. The aim of this paper is to review the major findings from a large representative and comprehensive national survey in Britain, which assessed the degree to which the numbers of teeth and dentures affected older people's perceived ease of eating, their nutrient intakes and their nutritional status.

\section{Sample and methods}

A sub-sample of people participating in the National Diet and Nutrition Survey (NSNS) of adults aged 65 and over ${ }^{21}$ had an oral examination and an oral health interview. Data from the questionnaire and the clinical examination were linked, along with data from the four-day dietary survey $^{22}$.

There were two samples. The free-living sample lived in their own home, whilst the institution group were cared for in residential homes and nursing homes on a full-time basis. The free-living sample was selected using a multistage random probability design. Households containing eligible adults were identified and a sample of individuals was selected using probabilities required to produce the target sample sizes, with only one person being sampled per household. Institutions were excluded from this sample ${ }^{21}$. The institution sample was selected from the postal districts that contained the postal sectors of the free-living sample. A total of 178 institutions were randomly selected, with further institutions being selected as reserves for use if the original selections proved to be ineligible or unproductive.

A target sample size for the oral health survey in the region of 1000 subjects was set, of whom 50\% should be dentate and the remainder edentate. Individual weights were calculated based on the design of the original stratification, and on known biases within the sample resulting from the minor sampling and response differences between groups. Full details of the methods of selection and procedures for weighting are published elsewhere $^{21,22}$

Participants underwent a dental examination by a trained and calibrated examiner. They were then asked by a trained interviewer to rate the amount of difficulty they had eating certain key foods, or the amount of difficulty they anticipated that they would have if they were to attempt to eat them. The dietary survey collected detailed information about the quantities of foods and nutrients consumed by the sample of elderly people using a four-day weighed dietary record of all food and drink consumed, both in and out of the home. Demographic and anthropometric data and measurements of the levels of certain nutrients in blood and urine were also collected. An interviewer-administered structured questionnaire collected general information about dietary habits, details of dietary supplements and medicines taken, and background information about physical activities and health. Blood and urine were collected by trained nurses and analysed by the Medical Research Council's Dunn Nutrition Unit in Cambridge. For certain assays, external or national external quality assurance schemes operated. Only the results on key nutrients for the free-living sample are reported here because the number of dentate individuals in the institution group for whom blood analyte data were available was small.

This paper examines whether there is any demonstrable relationship between the number and position of an individual's teeth and their perceived ability to eat a range of common foods, the nutrient intake and selected blood analytes. The nutrients and analytes used in the analysis were specifically chosen as those liable to have been affected by the reported restrictions in food consumption. Further details of the methods are given in Finch $e t a l{ }^{21}$ and full data tables in Steele et $a l^{22}$.

\section{Statistical analysis}

Computerised data were converted for analysis by the statistical program SPSS. Key socio-demographic, medical, dietary and nutritional variables were combined with the dental data. Data presented are for the two samples, which are kept separate.

For comparison of means, a two sample $t$-test was used where the data were normally distributed and a Mann- 
Whitney or Kruskal-Wallis test where the data showed significantly abnormal distribution. For comparisons of proportions, a chi-square analysis was used. Multivariate logistic modelling was used to ensure allowance for the potential confounding variables of age, sex, social class and region of origin during the assessment of the effect of oral status on diet, before assessing statistical significance. These four variables were entered into the model on all occasions along with the oral health variable being tested.

Odds ratios for the variables 'number of natural teeth and 'number of posterior occlusal pairs' were estimated based on a continuous rather than categorical scales. Regression coefficients for the variables 'number of natural teeth' and 'number of posterior occluding pairs' were estimated based on a continuous scale. Sex, social class, region of residence, partial denture wearing and dental status were entered into the equation as binary (dummy) variables. Assumptions of normality, linearity and equality of variances were tested. $\log _{10}$ transformation was performed where there was deviation from normality. The term 'not statistically significant' indicates significance at less than the 5\% level.

\section{Results}

The sample for the oral health survey was drawn from those who completed the four-day weighed dietary record, representing 59\% of the issued sample for the dietary survey. After correction for sub-sampling of the edentate group, but before the application of sample weights, $69 \%$ of the food diary sample took part in the oral health survey. For the institution group, 67\% (unweighted) of the food diary group remained in the sample that underwent the dental examination. In total, 407 dentate and 346 edentulous participants were examined in the free-living group. In the institution group there were 57 dentate and 139 edentulous participants. Further details of response rate can be found in Finch et $a l_{.}{ }^{21}$ and Steele $e t a l^{22}$.

There were significant differences in the results for freeliving people and those in institutions, so the results for the free-living and institutional samples are presented separately.

Free-living sample: difficulty eating specified foods Among the edentate, $50 \%$ had difficulty eating or could not eat apples at all. Nuts (42\%), raw carrots (41\%), welldone steaks (33\%), tomatoes (20\%), lettuce (17\%) and toast (13\%) were also difficult to eat for many edentate people and almost one in five edentate participants said that they could not eat raw carrots or nuts at all. Smaller percentages of edentate people also said that they could not eat apples (12\%), well-done steaks (8\%), crisps (4\%), lettuce $(4 \%)$, oranges $(3 \%)$, tomatoes $(2 \%)$, chocolates (2\%) and toast (2\%) at all. When compared with the dentate, the edentate had significantly greater difficulty in
Table 1 Percentage of participants who reported that they could eat only with some difficulty or could not eat at all various types of food, analysed by dental status; free-living group (weighted data)

\begin{tabular}{lccl}
\hline Type of food & \% Dentate & \% Edentate & Odds ratio $(\mathrm{Cl}) \dagger$ \\
\hline Weighted base & 418 & 287 & \\
Tomatoes & $3 \ddagger$ & 20 & $3.6(2.42-5.51)^{\star \star \star}$ \\
Raw carrots & 19 & 41 & $2.0(1.35-3.07)^{\star \star \star}$ \\
Roast potatoes & 3 & 8 & $1.1(0.45-2.95) \mathrm{ns}$ \\
Lettuce & 4 & 17 & $1.9(0.99-3.62) \mathrm{ns}$ \\
Well-done steaks & 20 & 33 & $1.7(1.10-2.61)^{\star}$ \\
Apples & 28 & 50 & $1.6(1.10-2.32)^{\star \star \star}$ \\
Oranges & 4 & 11 & $1.3(0.64-2.84) \mathrm{ns}$ \\
Nuts & 24 & 42 & $1.5(1.03-2.22)^{\star \star \star}$ \\
Crisps & 5 & 10 & $1.0(0.50-2.02) \mathrm{ns}$ \\
\hline
\end{tabular}

ns, $P>0.05 ;{ }^{*} P<0.05 ;{ }^{* \star} P<0.01 ;{ }^{* \star \star} P<0.001$

† Odds ratio and significance level refer to unweighted data.

¥ Percentages refer to weighted data.

eating tomatoes, raw carrots, apples, nuts $(P<0.001)$, lettuce and well-done steaks $(P<0.01)$ after statistical correction for the confounding effects of age, sex, social class and region of origin (Table 1).

Among people with teeth, the number of natural teeth significantly affected the ability to eat some foods. Apples were a particularly good example: $45 \%$ of people with one to 10 teeth had some difficulty eating them or could not eat them at all, whereas only $12 \%$ of those with 21 or more teeth had the same limitation. All people with 21 or more teeth could eat sliced bread, crusty bread, toast, cheese, tomatoes, roast potatoes, cooked greens and chocolates easily, and $86 \%$ or more could eat with ease all of the other foods listed. The odds ratios were 0.9 for the relationships between number of teeth and foods such as raw carrots, apples, nuts $(P<0.001)$, well-done steaks and crisps $(P<0.05)$, after correction for confounding variables (Table 2 ).

\section{Free-living sample: nutrient intake}

Edentate people had significantly lower intakes of nonstarch polysaccharides (fibre), intrinsic and milk sugars $(P<0.001)$, protein, calcium, riboflavin, niacin, pantothenic acid, vitamin C $(P<0.01)$, non-haem iron, thiamin and vitamin $\mathrm{E} \quad(P<0.05)$ (Table 3$)$. The differences were particularly large for intake of nonstarch polysaccharides: $14 \mathrm{~g} \mathrm{day}^{-1}$ for the dentate, $11 \mathrm{~g} \mathrm{day}^{-1}$ for the edentulous. Among people with natural teeth, those with more teeth had significantly greater mean daily intakes of non-starch polysaccharides, total carbohydrate, intrinsic and milk sugars (fibre) $(P<$ 0.001), energy, calcium, non-haem iron $(P<0.01)$, protein, fat and vitamin $\mathrm{C}(P<0.05)$, after adjusting for sex, social class, region of origin and partial denture wearing. There were similar differences between the average intakes of those with differing numbers of posterior occluding pairs of natural teeth (POPs) for a wide range of nutrients; only fat, non-milk extrinsic sugars and haem iron did not show significantly lower average 
Table 2 Percentage of dentate participants who reported they could eat only with some difficulty or could not eat at all various types of food, odds ratio and statistical significance level analysed by number of natural teeth; free-living group (weighted data)

\begin{tabular}{|c|c|c|c|c|c|}
\hline Type of food & $\% 1-10$ teeth & $\% 11-20$ teeth & $\% 21+$ teeth & All dentate & Odds ratio $(\mathrm{Cl}) \dagger$ \\
\hline Weighted base & 135 & 167 & 124 & 426 & \\
\hline Crusty bread & 1 & 1 & 0 & 1 & $1.0(0.86-1.07) \mathrm{ns}$ \\
\hline Toast & 12 & 5 & 0 & 5 & $0.9(0.86-0.96)^{\star \star \star}$ \\
\hline Tomatoes & 6 & 2 & 0 & 3 & $0.9(0.81-0.93)^{\star \star \star}$ \\
\hline Raw carrots & 32 & 18 & 5 & 19 & $0.9(0.86-0.92)^{\star * *}$ \\
\hline Roast potatoes & 4 & 4 & 0 & 3 & $0.9(0.87-1.02) \mathrm{ns}$ \\
\hline Lettuce & 8 & 2 & 0 & 4 & $0.9(0.87-0.98)^{\star *}$ \\
\hline Sliced cooked meats & 6 & 3 & 1 & 4 & $0.9(0.87-0.98)^{\star}$ \\
\hline Well-done steaks & 25 & 22 & 14 & 20 & $0.9(0.91-0.97)^{\star \star \star}$ \\
\hline Apples & 45 & 26 & 12 & 28 & $0.9(0.90-0.95)^{\star \star \star}$ \\
\hline Oranges & 7 & 1 & 4 & 4 & $0.9(0.88-0.99)^{\star}$ \\
\hline Nuts & 41 & 24 & 7 & 24 & $0.9(0.89-0.95)^{\star \star \star}$ \\
\hline Crisps & 10 & 4 & 2 & 5 & $0.9(0.89-0.99)^{\star}$ \\
\hline Chocolates & 5 & 2 & 0 & 2 & $0.9(0.80-0.95)^{\star \star}$ \\
\hline
\end{tabular}

ns, $P>0.05 ;{ }^{\star} P<0.05 ;{ }^{* \star} P<0.01 ;{ }^{* \star \star} P<0.001$

$\dagger$ Odds ratio and significance level refer unweighted data.

$\ddagger$ Percentages refer to weighted data.

intakes with fewer posterior occluding pairs after correction for confounding factors.

\section{Free-living sample: blood analytes}

Amongst the dental sample, 490 gave a sample of blood for analysis. There was a general trend for many of the analytes towards higher values for the dentate and for those with most natural teeth. Dental status was not associated with the red cell count, the biochemical indicators of the $\mathrm{B}$ group vitamins and of vitamin $\mathrm{D}$ when confounding factors were taken into account. There were large and statistically significant differences between dentate and edentate people for mean plasma ascorbate level $(P<0.05)$, and a significant trend according to the number of teeth and posterior occluding pairs of teeth (POPs) $(P<0.01)$ (Table 4$)$. The ascorbate values for the edentate were around $20 \%$ lower than for the dentate

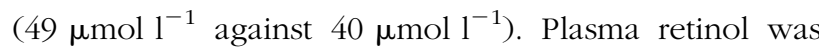
also significantly lower in the edentate than the dentate $(P<0.01)$ but was not significantly related to numbers of teeth and POPs after confounding factors had been controlled (Table 4).

\section{The institution sample}

Large percentages of people in institutions said they had difficulty eating some food items because of their teeth. Differences between dentate and edentate were often rather small in the institution sample and there were no

Table 3 Daily intake of nutrients and linear regression coefficients, adjusted for age, sex, social class, region of residence and partial denture wearing amongst participants, analysed by dental status; free-living

\begin{tabular}{|c|c|c|c|c|}
\hline \multirow{4}{*}{$\begin{array}{l}\text { Weighted base† } \\
\text { Unweighted base }\end{array}$} & Dentate & Edentate & \multirow[b]{4}{*}{ Regression coefficientł $(95 \% \mathrm{Cl})$} & \multirow[b]{4}{*}{ Significance level } \\
\hline & 418 & 287 & & \\
\hline & 373 & 317 & & \\
\hline & Mean & Mean & & \\
\hline Energy (kcal) & 1768 & 1583 & $54.3(-12.2,120.9)$ & 0.11 \\
\hline Protein (g) & 68 & 60.1 & $3.4(0.9,5.8)$ & 0.007 \\
\hline Fat $(g)$ & 69 & 63.9 & $1.1(-2.4,4.6)$ & 0.54 \\
\hline Total carbohydrate $(\mathrm{g})$ & 217 & 195 & $6.6(-2.3,15.6)$ & 0.15 \\
\hline Intrinsic and milk sugars (g) & 43 & 34 & $4.7(2.2,7.2)$ & $<0.001$ \\
\hline Non-starch polysaccharide (g) & 14 & 11.0 & $2.7(1.6,3.8)$ & $<0.001$ \\
\hline Calcium (mg) & 834 & 722 & $56.6(12.9,100.3)$ & 0.01 \\
\hline Haem iron (mg) & $0.7(0.8) \S$ & $0.6(0.71) \S$ & $0.02 \rrbracket(-0.03,0.20)$ & 0.49 \\
\hline Non-haem iron (mg) & 10.3 & 8.8 & $0.64(0.06,1.22)$ & 0.03 \\
\hline Thiamin (mg) & $2.3(1.4)$ & $1.3(1.2)$ & $0.08 \rrbracket(0.01,0.14)$ & 0.03 \\
\hline Riboflavin (mg) & $2.6(1.6) \S$ & $1.5(1.3) \S$ & $0.109(0.03,0.16)$ & 0.002 \\
\hline Niacin equivalent (mg) & 32 & 27 & $2.0(0.4,3.6)$ & 0.01 \\
\hline Pantothenic acid (mg) & $6(5) \S$ & $4(4) \S$ & $0.09 \emptyset(0.03,0.15)$ & 0.003 \\
\hline Vitamin C (mg) & $81(6) \S$ & $60(5) \S$ & $0.079(0.02,0.12)$ & 0.006 \\
\hline Vitamin E (mg) & $14(8) \S$ & $8(7) \S$ & $0.11 \rrbracket(0.01,0.21)$ & 0.04 \\
\hline
\end{tabular}

† Means were calculated using weighted data.

¥ Linear regression analyses were carried out using unweighted data.

$\S$ Exponential of the mean and median of the $\log _{10}$ values for daily intake of nutrients.

ๆ Regression coefficients after $\log _{10}$ transformation. 
Table 4 Haematological and biochemical indices and linear regression coefficients, adjusted for age, sex, social class, region of residence and partial denture wearing amongst dentate participants, analysed by dental status; free-living group

\begin{tabular}{|c|c|c|c|c|c|}
\hline \multirow{3}{*}{ Weighted base $\dagger$} & Dentate & Edentate & & \multirow[b]{3}{*}{ Regression coefficient $\neq(95 \% \mathrm{Cl})$} & \multirow[b]{3}{*}{ Significance level } \\
\hline & 309 & 199 & & & \\
\hline & Mean & Mean & & & \\
\hline \multirow[t]{2}{*}{ Plasma retinol $\left(\mu \mathrm{mol} \mathrm{I}^{-1}\right)$} & $\begin{array}{l}49 \\
2.3(2.2) \S\end{array}$ & $\begin{array}{l}40 \\
2.1(2.0) \S\end{array}$ & & $\begin{array}{l}5.17(0.80,9.55) \\
0.030(0.009,0.052) \emptyset\end{array}$ & $\begin{array}{l}0.02 \\
0.005\end{array}$ \\
\hline & 0 POPs & 1-4 POPs & $5+\mathrm{POPs}$ & & \\
\hline $\begin{array}{l}\text { Plasma ascorbate }(\text { vitamin } C)\left(\mu \mathrm{mol} \mathrm{I}^{-1}\right) \\
\text { Plasma retinol }\left(\mu \mathrm{mol} \mathrm{I} \mathrm{I}^{-1}\right)\end{array}$ & $\begin{array}{l}42.88 \\
2.30(2.24)\end{array}$ & $\begin{array}{l}53.47 \\
2.24(2.14)\end{array}$ & $\begin{array}{l}53.09 \\
2.31(2.24) \S\end{array}$ & $\begin{array}{l}1.40(0.48,2.32) \\
0.002(-0.002,0.006) \emptyset\end{array}$ & $\begin{array}{l}0.003 \\
0.49\end{array}$ \\
\hline
\end{tabular}

† Means were calculated using weighted data.

‡ Linear regression analyses were carried out using unweighted data.

$\S$ Exponential of the mean and median of the $\log _{10}$ values for daily intake of nutrients.

I) Regression coefficients after $\log _{10}$ transformation.

consistent trends or significant differences between the dentate and the edentate. Comparing edentate people living in institutions with edentate free-living participants, the former were even more likely to report problems eating than their free-living counterparts. In institutions, $53 \%$ said they had problems eating or could not eat apples (50\% among free-living). There were larger differences for raw carrots (51\% against 41\%), well-done steak (50\% against 33\%) and nuts (57\% against $42 \%)$. A number of foods such as nuts (35\%), raw carrots (29\%), apples (24\%), well-done steak (18\%), lettuce (6\%) and toast $(5 \%)$ could not be eaten at all by people in institutions (data for dentate and edentate combined).

The mean intakes of most nutrients were lower than those found in the free-living except for carbohydrate, non-milk extrinsic sugars and calcium, for which intake values were very similar. In the institution sample, there was little difference between the dentate and edentate subjects. Nutrient intake values for both were generally closest to those of the edentate members of the free-living sample. The institution group had a much higher mean intake of non-milk extrinsic sugars (77-81 g day ${ }^{-1}$ ) than the free-living sample $\left(54-56 \mathrm{~g} \mathrm{day}^{-1}\right)$. As the numbers with natural teeth in the institution group were small, intake data are not presented by number of teeth.

Plasma ascorbate values were very low in older adults living in institutions. The median value for the dentate was $31.0 \mu \mathrm{mol} \mathrm{l}^{-1}$ but only $11.4 \mu \mathrm{mol} \mathrm{l}^{-1}$ for the edentate $(P<0.05)$. The value for the dentate is low compared with the group with the lowest median value found in the freeliving sample: the edentate free-living $\left(40.1 \mu \mathrm{mol}^{-1}\right)$. No other blood analytes showed a significant relationship with dental state in the institution group.

\section{Discussion}

This large population-based study shows that dental status in older people was associated with perceived ability to eat a number of foods, and those difficulties were reflected in the amount of fruit, vegetables and nutrients, and particularly fibre eaten. The differences in diet by dental status was also related to serum ascorbate and retinol levels.

Being edentulous is relatively common in older people. In 1998, 46\% of adults aged 65 years and over in the United Kingdom were edentulous ${ }^{23}$. Their difficulties with eating are particularly marked. Twice as many edentate than dentate had difficulties eating oranges, apples, carrots, toast and roast potatoes, and the edentate were twice as likely to consume insufficient vegetables $\left(<400 \mathrm{~g} \mathrm{day}^{-1}\right)$. In total $10 \%$ of them had difficulty or could not eat 10 of the 16 types of food about which they were questioned. Retention of teeth into older age appears to be of some importance in order to provide the functional means to consume a varied diet, particularly fruit and vegetables.

Amongst people with teeth, ease of eating was clearly influenced by the number of teeth present, with chewing becoming easier with a greater number of natural teeth. For those with over 20 teeth, there were few foods that could not be managed easily by almost everyone. Posterior occluding pairs (POPs) are pairs of natural premolar and molar teeth that contact each other when the mouth is closed normally and indicate chewing capacity. Foods that needed more chewing were most affected by the number of POPs. For example, $20 \%$ of participants with one to four POPs compared with $8 \%$ of those with five or more POPs reported difficulty with eating apples, supporting the findings from previous studies $^{24,25}$. Although the maximum adult dentition is 32 teeth, around 28 teeth would be considered a complete dentition, so some limited tooth loss is still consistent with adequate function. However, limiting this tooth loss to ensure more than 20 natural teeth, and/or five or more POPs, can make a substantial impact on the ability to enjoy a varied diet.

These findings suggest that eating ability, and potentially food choice, are affected by oral health; specifically by the number and distribution of natural teeth. How may that translate into nutritional intake? 
Nutrient intake of older people was associated with dental status. Being edentulous had a significant relationship with the intake of several key nutrients amongst free-living older people. They consumed less food energy and significantly less protein, intrinsic and milk sugars, non-starch polysaccharide (fibre), calcium, non-haem iron, niacin and vitamin $\mathrm{C}$ than dentate people. These relationships have taken account of the important confounders, such as age, social class and gender. At a population level, the relationship is real and significant. Of course this does not mean that all older people without teeth are malnourished, but those with, for example, coexisting ill health or disability may be particularly vulnerable to reduced intakes.

A relationship between nutrient intake and the number and distribution of teeth was more difficult to establish. Nevertheless, two findings are of particular interest. The first is that people with more than 20 natural teeth consumed more of the majority of nutrients than those with fewer. This provides further evidence that possession of more than 20 natural teeth is consistent with a good dietary capability and optimum nutritional intake. The second important finding is that intake of non-starch polysaccharide (dietary fibre) was much higher in people with more teeth and significantly associated with the number of occluding pairs of posterior teeth (POPs). Intake of intrinsic and milk sugars, derived from foods such as fresh fruit and its derivatives, was also significantly associated with having more occluding pairs of natural teeth. The findings relating to non-starch polysaccharide provide confirmation of the reports by Moynihan et $a l .{ }^{15}$ and Joshipura et $a l .{ }^{18}$ that dental state is related to intake of dietary fibre. Non-starch polysaccharides are an important component of diet so the relationship with oral health in the elderly is of considerable importance.

These relationships may in large part be related to problems eating fruits and vegetables. Using the same data set, Moynihan et $a l .{ }^{15}$ showed that edentate older people consumed $181 \mathrm{~g} \mathrm{day}^{-1}$ of fruit and vegetables compared with $267 \mathrm{~g}$ day $^{-1}$ by the dentate. The majority of the difference was due to fruit consumption patterns: $79 \mathrm{~g}$ day $^{-1}$ in the edentate compared with $128 \mathrm{~g} \mathrm{day}^{-1}$ in the dentate. Edentate subjects were twice as likely to consume insufficient quantities of fruit and vegetables $\left(<400 \mathrm{~g} \mathrm{day}^{-1}\right)$. There was a similar increase in fruit and vegetable intake with increasing number of teeth and POPs, and the risk of insufficient intake of fruit and vegetables reduced with each additional POP.

A variety of other nutrients (including food energy, protein, non-milk extrinsic sugars, calcium, non-haem iron, niacin and vitamin C) showed a reduced intake with a reduced dentition or reduced POPs. However, the intake values for dentate individuals with very few teeth were higher than for those with none, suggesting that retention of even a few natural teeth or contacts may often be of some value.
The differences in nutrient intake between dentate and edentate subjects that were so evident in the free-living sample were not manifest in the institution sample. In an institutional setting food is generally provided irrespective of eating ability, and the diet is most likely to be tailored to the masticatory capacity of those with the poorest eating ability. This was borne out in the results; intake values amongst people living in institutions were generally closest to the values for edentulous free-living people. The very high level of intake of non-milk extrinsic sugars consumed in institutions, though, is a source of some considerable concern. Combined with poor hygiene, which is common in institutions ${ }^{22}$, high intake of extrinsic sugars will increase substantially the risk of dental caries, which may be a serious threat to the remaining teeth in those who have them.

This study also provides unequivocal evidence that dental status is related to two haematological and biochemical measures of nutritional status: plasma ascorbate and plasma retinol. Dental status was not significantly associated with haematological and biochemical measures for the other key nutrients for which intake values did vary with oral health. The findings are similar to those of Makila ${ }^{26,27}$, Carlos and Wolfe ${ }^{14}$ and Posner et $a l^{28}$, although in some cases dental status affected the blood analytes for vitamin E and plasma iron, as well as vitamins $\mathrm{A}$ and $\mathrm{C}$. The study design and ability to control for confounding variables may partly account for the non-significance of these variables in this study.

Plasma ascorbate was significantly related to whether older people were dentate or not, and to the number of occluding pairs of teeth. About one-fifth of edentate people said they could only eat vitamin C-rich foods, specifically raw fruit and vegetables, with difficulty or not at all ${ }^{19}$. This impacted both on intake values and on plasma ascorbate levels. The relationship between dental state and vitamin $\mathrm{C}$ appears to be both real and potentially important to general health. The impact of dental state on the plasma values was perhaps greater than one may expect given the impact on the measures of intake. Vegetables and fruit that have been softened by cooking may be manageable by those with fewer teeth, but may have lost some vitamin $\mathrm{C}$. The presence of adequate functional natural teeth may have an effect on nutrition and health by affecting the way food is prepared, as well as by affecting food choice. In institutions, where catering has to meet the needs of the people with the poorest dentitions, the median plasma ascorbate value for the edentate was very low indeed: $11.4 \mu \mathrm{mol} \mathrm{l}^{-1}$, compared with $40.1 \mu \mathrm{mol} \mathrm{l}^{-1}$ for free-living edentulous people and $48.7 \mu \mathrm{mol} \mathrm{l}^{-1}$ for the free-living dentate.

This study has shown that the dental status of older people can have an impact on their ability to eat, affecting food choice and preparation, and ultimately the intake and blood levels of some key nutrients. With oral health showing rapid improvements ${ }^{23}$, the potential to improve 
nutrition, and so general health, in the elderly is considerable. This potential can be exploited only if the relationships between oral health and nutrition are widely understood.

\section{Acknowledgements}

The National Diet and Nutrition Survey of people aged 65 years and over was funded jointly by the Ministry of Agriculture, Fisheries and Food (MAFF) and the Department of Health, and conducted by Social and Community Planning Research (now the National Centre for Social Research) in conjunction with the Medical Research Council's Dunn Nutrition Unit (now the MRC Centre for Human Nutrition Research), the University of Newcastle, University College London and the University of Birmingham. Responsibility for the National Diet and Nutrition Survey programme transferred from MAFF to the Food Standards Agency on its establishment in April 2000. The views expressed in this paper are not necessarily those of the Department of Health, MAFF or the Food Standards Agency.

\section{References}

1 Geissler CA, Bates JF. The nutritional effects of tooth loss. Am. J. Clin. Nutr. 1984; 39: 478-89.

2 Moynihan PJ. The relationship between diet, nutrition and dental health: an overview and update for the 90s. Nutr. Res. Rev. 1995; 8: 193-224.

3 Papas AS, Palmer CA, Rounds MC, Russell RM. The effects of denture status on nutrition. SCD Special Care In Dentistry 1998; 18: 17-25.

4 Chauncey HH, Muench ME, Kapur KK, Wayler AH. The effect of the loss of teeth on diet and nutrition. Int. Dent. J. 1984; 34: 98-104.

5 Papas AS, Palmer CA, Rounds MC, Herman J, McGrandy R, Hatz $\mathrm{S}$, et al. Longitudinal relationships between nutrition and oral health. Ann. NY Acad. Sci. 1989; 561: 124-42.

6 Hollister MC, Weintraub JA. The association of oral status with systemic health, quality of life, and economic productivity. J. Dent. Educ. 1993; 57: 901-11.

7 Brodeur JM, Laurin D, Vallee R, Lachapelle D. Nutrient intake and gastrointestinal disorders related to masticatory performance in the edentulous elderly. J. Prosth. Dent. 1993; 70: $468-73$.

8 Leao A, Sheiham A. Relation between clinical dental status and subjective impacts on daily living. J. Dent. Res. 1995; 74(7): 1408-13

9 Atchison KA, Dolan T. Development of the Geriatric Oral Health Assessment Index. J. Dent. Educ. 1990; 54: 680-7.

10 Locker D. The burden of oral disorders in a population of older people. Community Dent. Health 1992; 9: 109-24.

11 Locker D. Subjective reports of oral dryness in an older adult population. Community Dent. Oral Epidemiol. 1993; 21: $165-8$.

12 Gilbert GH, Heft MW, Duncan RP. Mouth dryness as reported by older Floridians. Community Dent. Oral Epidemiol. 1993; 21: 390-7.

13 Wayler AH, Muench ME, Kapur KK, Chauncey HH. Masticatory performance and food acceptability in persons with removable partial dentures, full dentures, and intact natural dentition. J. Gerontol. 1984; 39: 284-9.

14 Carlos JP, Wolfe MD. Methodological and nutritional issues in assessing oral health of aged subjects. Am.J. Clin. Nutr. 1989; 50: $1210-8$

15 Moynihan PJ, Snow S, Jepson NJA, Butler TJ. Intake of nonstarch polysaccharide (dietary fibre) in edentulous and dentate persons: an observational study. Br. Dent. J. 1994; 177: $243-7$.

16 Krall E, Hayes C, Garcia R. How dentition status and masticatory function affect nutrition intake. J. Am. Dent. Assoc. 1998; 129: 1261-9.

17 Ranta K, Touminen R, Paunio I, Sepponen R. Dental status and intake of food items among an adult Finnish population. Gerodontics 1988; 4: 32-5.

18 Joshipura KJ, Willett WE, Douglass CW. The impact of edentulousness on food and nutrient intake. J. Am. Dent. Assoc. 1996; 127: 459-67.

19 Sheiham A, Steele JG, Marcenes W, Finch S, Walls AWG. The impact of oral health on ability to eat certain foods; findings from the National Diet and Nutrition Survey of older people in Great Britain. Geriodontol. 1999; 16: 11-20.

20 Sheiham A, Steele JG, Marcenes W, Lowe C, Finch S, Bates CJ, Prentice A, Walls AWG. The relationship between dental status, nutrient intake and nutritional status, amongst older people. J. Dent. Res. (in press).

21 Finch S, Doyle W, Lowe C, Bates CJ, Prentice A, Smithers G, Clarke PC. National Diet and Nutrition Survey: People aged 65 and over. Vol. 1: Report of the Diet and Nutrition Survey. London: HMSO, 1998.

22 Steele JG, Sheiham A, Marcenes W, Walls AWG. National Diet and Nutrition Survey: People aged 65 years and over. Vol. 2. Report of the Oral Health Survey. London: HMSO, 1998.

23 Kelly M, Steele J, Nuttall N, et al. Adult Dental Health Survey. Oral Health in the United Kingdom 1998. London: HMSO, 2000.

24 Leake JL. An index of chewing ability. J. Public Health Dent. 1990; 4: 262-7.

25 Aukes JNSC, Kayser AF, Felling AJA. The subjective experience of mastication in subjects with shortened dental arches. J. Oral Rehab. 1988; 15: 321-4.

26 Makila E. Effects of complete dentures on the dietary habits and serum thiamine, riboflavin, and ascorbic acid levels in edentulous persons. Suom Hammaslaak. Toim. 1968; 64: 107-52.

27 Makila E. Effects of complete dentures on dietary intake and serum levels of pantothenic acid, folic acid and iron in edentulous persons. Suom Hammaslaak. Toim. 1969; 65: 299-311.

28 Posner BM, Jette A, Smigelski C, Miller D, Mitchell P. Nutritional risk in New England elders. J. Gerontol. 1994; 49: M123-32. 